\title{
Past, present and future
}

\author{
Passado, presente e futuro
}

Renato S. Procianoy*

U m novo mandato está iniciando. O editor-chefe e os editores associados e executivos foram reconduzidos pela Sociedade Brasileira de Pediatria para um novo período de quatro anos na editoria do Jornal de Pediatria. O Conselho Editorial está sendo renovado contando com a participação de professores e pesquisadores nacionais e internacionais de reconhecido saber, e, a partir deste número, estão sendo alteradas algumas políticas editoriais do Jornal de Pediatria.

O Jornal de Pediatria, revista oficial da Sociedade Brasileira de Pediatria (SBP), tem sido modificado nos últimos anos com o objetivo de alcançar maior visibilidade e se adaptar aos padrões editoriais internacionais.

Em março de 2001, foi lançada a página eletrônica com acesso livre, necessitando de um registro gratuito que demora poucos segundos para ser efetuado (www.jped.com.br). Todos os artigos publicados a partir de janeiro de 2000 estão disponíveis na versão integral em português e inglês. Os artigos publicados de janeiro de 1994 a dezembro de 1999 estão disponíveis na versão integral em português, e os resumos estão disponíveis também em inglês.

A indexação na SciELO (www.scielo.br), em julho de 2002, aumentou a visibilidade nacional, resultando em mais artigos brasileiros submetidos a publicação. A SciELO é uma base de dados eletrônica de revistas latino-americanas que inclui também Espanha e Portugal.

A recompensa do trabalho desenvolvido pelo conselho editorial do Jornal de Pediatria e pela diretoria da SBP foi a indexação no Index Medicus/MEDLINE em agosto de 2003. Todos os artigos publicados no Jornal de Pediatria a partir de janeiro de 1994 foram incluídos no PubMed (www.pubmed.org), e a pesquisa bibliográfica disponibiliza os artigos com links para as versões em português e inglês em texto integral.

A preocupação em aumentar a divulgação internacional do material publicado levou-nos a incluir o Jornal de Pediatria

* Editor, Jornal de Pediatria e JPED.

Como citar este artigo: Procianoy RS. Past, present and future. J Pediatr (Rio J). 2006;82:1. no sistema Crossref em maio de 2005. O sistema Crossref utiliza identificadores digitais (digital object identifier, DOI) para estabelecer links entre artigos e outros tipos de materiais das mais importantes revistas internacionais. Todos os artigos publicados no Jornal de Pediatria a partir de janeiro de 2004 foram incluídos no sistema Crossref.

O resultado dessas ações trouxe resultados positivos. Seis números regulares e dois suplementos temáticos são publicados anualmente. O número de artigos tem se mantido estável desde 2002: 60 originais, seis revisões e sete relatos de casos por ano, além de 12 artigos de revisão por suplemento. 0 número global de artigos submetidos aumentou de 140 em 2000 para 390 em 2005; o número de artigos estrangeiros submetidos em 2005 foi 15, e o número de acessos ao site JPED alcançou a média mensal de 60.000. Neste momento, estamos trabalhando na criação de um sistema on-line de submissão e revisão de artigos. Esse sistema trará maior agilidade e transparência ao gerenciamento dos processos de submissão e revisão, que atualmente são feitos por e-mail.

É importante salientar que, sem o constante apoio das diretorias da Fundação Sociedade Brasileira de Pediatria e da Sociedade Brasileira de Pediatria, esses resultados não teriam sido alcançados.

Ainda assim, temos muito trabalho pela frente. A internacionalização do Jornal de Pediatria é, atualmente, o principal objetivo do Conselho Editorial. Apesar de nossos artigos estarem livremente disponíveis na Internet, em versão integral, tanto em inglês quanto em português, o MEDLINE não reconhece a versão em inglês, por não estar disponível no formato impresso.

Para resolvermos essa situação, a partir deste número, os artigos serão publicados exclusivamente em inglês na versão impressa da revista. No site, todos os artigos serão publicados em português e inglês, tanto em HTML quanto em PDF. Os sócios da SBP receberão uma cópia impressa do Jornal de Pediatria traduzida para o português.

Com essas modificações, esperamos estar dando mais um passo importante na qualificação do Jornal de Pediatria. 